\title{
Validation of Late Season Cornstalk Nitrate Test under Different Natural and Social Environments for Better Fertilizer Management in China
}

\author{
GUANGWEI HUANG \\ Graduate School of Global Environmental Studies, Sophia University \\ 7-1, Kioicho, Chiyodaku, Tokyo, 102-8554, Japan \\ ${ }^{*}$ Corresponding author E-mail: huang @ genv.sophia.ac.jp \\ http://dx.doi.org/10.13005/ojc/290413
}

(Received: August 25, 2013; Accepted: October 18, 2013)

\begin{abstract}
While the current food security is fulfilled in China, the substantial nitrogen fertilizer use has caused many far-reaching environmental problems. Therefore, reforming the fertilizer management is the key toward sustainable agriculture for 1.3 billion people. The present study is intended to test the applicability of a nitrogen fertilizer management approach for corn production developed in U.S. to regions with different climates in China. Through field work, it was found that the so-called Late Season Cornstalk Nitrate Test approach may have to be adapted to dry continental climate and irrigation water conditions, but meanwhile appeared workable under sub-humid warm temperate continental monsoon climate in China. A hypothesis was made to explain the findings and a simple cure was suggested. Moreover, the importance of applying this approach to China was discussed in relation to GHG emission reduction and national fertilizer subsidy policy. Finally, a new fertilizer management scheme was proposed.
\end{abstract}

Key words: Nitrogen fertilizer; cornstalk test; climate; irrigation water.

\section{INTRODUCTION}

China uses $7 \%$ of global water and $10 \%$ of the total arable land in the world to feed $20 \%$ of the world's population. Under such a condition, the use of nitrogen fertilizers to increase grain production has climbed from less than $100 \mathrm{~kg} / \mathrm{ha}$ in the $1980 \mathrm{~s}$ to $260 \mathrm{~kg} / \mathrm{ha}$ in 2005 on average across China. As a result, China has become the largest consumer of synthetic nitrogen in the world, accounting for $32 \%$ of the world's total nitrogen consumption ${ }^{1}$. While achieving the food security in China in the short-term, the substantial nitrogen fertilizer use has caused many environmental problems, such as nitrate contamination of groundwater, soil acidification and greenhouse gas emissions. Nitrate contamination of groundwater due to agricultural activities in China has been reported by Chen et al., ${ }^{2}$, Ju et al., ${ }^{3}$, and Yang and $\mathrm{Liu}^{4}$. Meanwhile, the proportion of soils with good inherent fertility in China has decreased from nearly $33 \%$ in 1980 to $20 \%$ in 1995 , resulting from unsustainable agricultural practices including the over-application of agrochemicals ${ }^{5}$. As soil health deteriorates, the application of more and more chemical fertilizers becomes necessary, thus creating a vicious cycle. Furthermore, the nitrogen 
use efficiency in China is only approximately 30\%, close to the global average of $33 \%$, but significantly lower than the average value of $42 \%$ in developed countries. To achieve the long-term food security in China, the optimal use of fertilizers is the key for maintaining high yields while minimizing negative impacts.

The Late Season Cornstalk Nitrate Test (LSCNT), developed at lowa State University ${ }^{6}$, has been considered as a reliable assessment of whether the crop had the right amount of nitrogen, too much nitrogen, or was nitrogen limited. This information combined with records of nitrogen fertilizer application can be very useful for making future management decisions. The basis for the test lies in the fact that corn plants deficient for nitrogen will usually remobilize stored nitrogen from the lower portions of the stalk and leaves to the developing grain; resulting in lower stalk nitrogen concentrations at the end of the season. As a result, corn plants taking more nitrogen than needed to attain maximum yield accumulate nitrate in their lower stalks at the end of the season. Thus the test will accurately indicate deficient, optimal, or excess nitrogen availability during the growing season. The underlying reason for over-fertilization is that corn plants show no visual symptoms that enable producers to recognize when above-optimal rates of nitrogen have been applied. This implies that producers can apply too much nitrogen year after year and never suspect a problem with their nitrogen management. The end-of-season cornstalk test makes it possible for producers to avoid this pitfall.

Although LSCNT has been practiced in U.S., its applicability to corns grown under different climate and much more intensive use of fertilizer has not been discussed so far.

Light intensity plays a major role in nitrate accumulation in crops because protein synthesis is dependent on photosynthesis to convert $\mathrm{NO}_{3}$ into amino acids. Studies have confirmed that a shorter photoperiod increased nitrate contents in crops such as leafy greens ${ }^{7-8}$. Meanwhile, it has often been observed that $\mathrm{NO}_{3}^{-}$concentration in herbage is high after a short period of drought, for two reasons ${ }^{9-10}$. Firstly, during the drought period the $\mathrm{NO}_{3}{ }^{-}$concentration builds up in the soil and most of the nitrogen is taken up in this form. Secondly, the moisture stress during the drought period causes dry matter yield depression, thereby resulting in less reduction of $\mathrm{NO}_{3}$ to organic nitrogen.

Therefore, the concern which motivated the present study is that weather or not the corn test developed in a humid continental climate is also valid in a dry continental climate with different social environment. Following this line of thought, an arid and corn-growing region in China was chosen for validating the corn test in China. Besides, as a further application, the corn test was used to diagnose nitrogen fertilizer use in another region in China which has a sub-humid warm temperate continental monsoon climate.

\section{Site description}

The Zhangye Basin along the middle reaches of the Heihe River was chosen as the main study area. Heihe River is the second largest inland river in China. Its main stream, with a length of 821 $\mathrm{km}$, originates from the Qilian Mountains of Qinghai Province, flows through the Zhangye Basin, which is part of the ancient Silk Road, and ends up in the Inner Mongolia Autonomous Region. Zhangye Basin covers an area of $1.08104 \mathrm{~km}^{\circ}$ extending from 38030 ' to 39050' N and 99 o10' to 100 o52' E. Along the main stream, the middle reaches of the Heihe River starts from the Yingluo Gorge and ends at the Zhengyi Gorge (Fig.1). The basin is characterized by a dry continental climate. The area of the irrigated farmlands in the basin is $2,360 \mathrm{~km}^{2}$. Grain crops, particularly seed corn, are densely cultivated and sustained by the continuous application of chemical nitrogen fertilizers.

Luan River flows northwards from its source in the province of Hebei into the province of Inner Mongolia, and then flows southeast back into Hebei to its mouth on the Bohai Sea. The catchment area is $44,900 \mathrm{~km}^{2}$ and the main channel length is 888 $\mathrm{km}$. It provides important water resources to Tianjin, Tangshan and Chengde cities, covering a population of $23,120,000$. Luan County is located in the middle reaches of the Luan River and has a sub-humid warm temperate continental monsoon climate. The land use in the Luan County is mainly agriculture. Crops include wheat, corn, bean, potato and rice. 
A comparison of climate characteristics between lowa State, Zhangye Basin and Luan County is compiled in Table 1. lowa State and Luan County are climatically similar to each other, and have much more precipitation but less sunshine duration than Zhangye Basin. Methodology

The procedure of LSCNT is to cut an 8-inch $(20.32 \mathrm{~cm})$ segment of the stalk between 6 (15.24 $\mathrm{cm})$ and 14 inches $(35.56 \mathrm{~cm})$ above the ground as shown in Fig. 2. Based on the measurement of nitrate concentration of that stalk portion, nitrogen use can be classified into four categories

\section{Low (< 250 ppm)}

Stalk nitrate concentrations in the Low range indicate a high probability that additional fertilizer or manure nitrogen would have resulted in higher yields. Visual signs of nitrogen deficiency usually are obvious when nitrate concentrations are within this range.

\section{Marginal (250-700 ppm)}

Stalk nitrate concentrations in the Marginal range indicate that nitrogen availability was very close to the minimal amount needed to maximize grain yields. Visual signs of nitrogen deficiency are less common when nitrate concentrations are in this range. Although yields usually are not adversely affected by nitrogen deficiencies of this magnitude, this range is too close to the economic penalties associated with nitrogen deficiencies to be the target for good nitrogen management.

\section{Optimum (700-2000 ppm)}

Stalk nitrate concentrations in the Optimum range indicate a high probability that the amount of soil, fertilizer, and manure nitrogen available during the growing season was sufficient to maximize profits for the producer.

\section{Excessive (> 2000 ppm)}

Stalk nitrate concentrations in the excessive range indicate a high probability that the amount of fertilizer or manure nitrogen applied was greater than necessary to maximize profits for the producer for this production year. Nitrate leaching to ground waters is a serious concern when corn stalks have nitrate concentrations in the excessive range. Nitrogen management practices used this year should be reviewed carefully and modified in the future to avoid over-fertilization with nitrogen which is not just uneconomic but also nonpoint source pollution of ground and surface waters.

In this way, the results of the test will indicate yield-limiting deficiency, an optimal concentration, or excessive nitrate levels and such information can help producers identify the lowest cost management practices that should increase profitability over time.

To validate this approach in the Zhangye Basin, corn plant samples were collected from fields in three villages and nitrate concentrations were measured approximately every $10 \mathrm{~cm}$ along each sample plant from the brace roots to the top flag leaf. The measuring method is to cut a sample corn plant into pieces and extract out plant juice of a volume between $0.3 \mathrm{ml}$ and $2 \mathrm{ml}$ from each portion of the plant by a squeezer, and measure its nitrate concentration with the Horiba compact nitrate ion meter (LAQUAtwin-B741), which is based on the colorimetric method of Gilbert ${ }^{11}$. The sensor was calibrated by the two-calibration mode with 300 ppm and 5000 ppm standard solutions on a daily base. Measuring nitrate distribution can serve as a confirmation that the segment of the stalk sampled according to LSCNT provides a good assessment of nitrate accumulation in the plant. Then, by combining the measurement result with information on the local nitrogen fertilizer use, the validity of LSCNT in the Zhangye Basin can be assessed.

In the Zhangye Basin, the investigation was carried out in three villages from August 8 to August 18, 2012. Gaozai and Genming villages are located respectively in the north and northeast part of the Zhangye City, where the irrigation water is the sewage mixed with river water from a tributary of the Heihe River. Yangjiazha village is in the southern part of the city and uses water from the Heihe River for irrigation. Corn plant samples were taken from the three fields and the sampling at each site was randomly performed. All on-site measurements of nitrate concentration were conducted under fine weather during daytime. Besides, the nitrate and ammonium $\left(\mathrm{NH}_{4}^{+}\right)$concentrations of irrigation water entering into the farmlands were also measured with the Horiba compact nitrate ion meter (LAQUAtwin- 
B743) for water and HACH Portable Meter (DR/890), respectively. The soil type is mainly sandy loam at all sites surveyed in this study. In Luan County, the survey for nitrate accumulation in corn plant was conducted in the same way as done in the Zhanye Basin under fine weather during daytime in September 2012.

\section{RESULTS}

At the two sites where sewage-dominated water was used for irrigation, the concentrations of nitrate in water entering into corn fields were found to be $20 \mathrm{mg} / \mathrm{L}$ in Gaozai village and $110 \mathrm{mg} / \mathrm{L}$ in the Genming village, respectively at the time of sampling. And the concentrations of ammonium $\left(\mathrm{NH}_{4}^{+}\right)$in the water were also tested at the same time and they were $6 \mathrm{mg} / \mathrm{L}$ and $0.2 \mathrm{mg} / \mathrm{L}$, respectively.

In the Yangjiazha village where the water from the Heihe River is used for irrigation, the nitrate concentration in the irrigation water was found to be $15 \mathrm{mg} / \mathrm{L}$.

Figure 3 shows nitrate concentration distributions along two corn stalks. One has the maximum root concentration of nitrate among all surveyed and was irrigated by sewage while the other has the minimum root concentration of nitrate and was irrigated by river water.

The two distributions show similar pattern. The nitrate concentration is highest at the brace roots and lowest at the top. However, the nitrate concentration in the river-water-fed plant decreased vertically much faster than the wastewater-fed plant. The mean nitrate concentrations of the segment designated by LSCNT approach are 3200 ppm for the sewage-irrigated plant and $1600 \mathrm{ppm}$ for the river-water-irrigated plant, respectively.
The fast decrease in nitrate content in river-water-irrigated corn stalk may be considered as representative of corns in arid region. The logic is that infrequent irrigating in arid region reduces crop nitrate uptake from soil and high irradiance promotes the conversion of nitrate to protein in the crop. When sewage is used, the supply is stable so that the crop nitrate uptake is enhanced leading to more build-up of nitrate in the crop.

In total, 10 mature corn plants were sampled in the Zhange Basin during the August 2012. Among them, five were grown with river water and their nitrate concentrations for the segment designated by LSCNT varied from $1560 \mathrm{ppm}$ to $1860 \mathrm{ppm}$. Meanwhile, for corn plants grown with wastewater water, the corresponding nitrate concentrations varied from $2900 \mathrm{ppm}$ to $3200 \mathrm{ppm}$. Following the classification of LSCNT, the nitrogen use in the Zhangye Basin may be judged as optimum for river-water-irrigated corn plant while excessive for wastewater-fed plant.

According to Su et al..$^{12}$, the total amount of nitrogen fertilizers applied on the corn fields in the Zhangye Basin was more than $450 \mathrm{~kg} / \mathrm{ha}$ in recent years. Sun and $\mathrm{Du}^{13}$ reported that nitrogen fertilizer rate in this region was $348 \mathrm{~kg} / \mathrm{ha}$. Meanwhile, experiments conducted by $\mathrm{Qin}^{14}$ showed that the optimal nitrogen application rate for corn production in the Zhangye Basin is $103 \mathrm{~kg} / \mathrm{ha}$. The local reality is opposed to the judgment by LSCNT. This suggests that there is a need to modify LSCNT to detect the overuse of nitrogen fertilizer in corn production in this arid region. At the time of measurement, the river water temperature was around $15{ }^{\circ} \mathrm{C}$ owing to its origin of snowmelt while the air temperature was around $30^{\circ} \mathrm{C}$. Therefore, a hypothesis is that when water with relatively low temperature enters into a corn plant, it cools down the lower portion of the plant while the temperature of the top part is

Table 1: Comparison of climate characteristics among three regions

average annual temperature $\left({ }^{\circ} \mathrm{C}\right)$ annual precipitation $(\mathrm{mm})$ total annual sunshine hours

\begin{tabular}{lccc}
\hline lowa & 10 & 850 & 2691 \\
Zhangye & 7 & 110 & 2970 \\
Luan County & 10.5 & 715 & 2651 \\
\hline
\end{tabular}




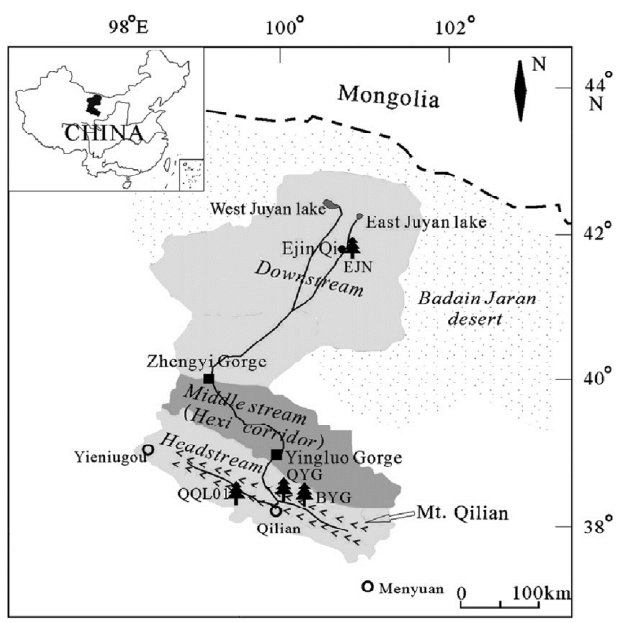

Fig. 1: Watershed of the Heihe River

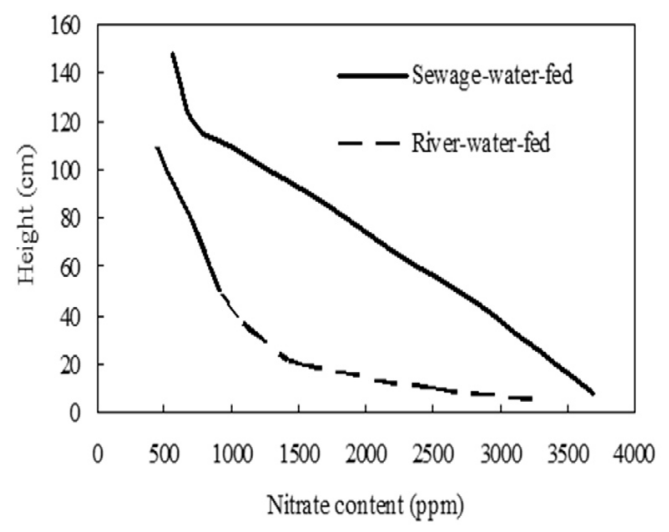

Fig. 3: Nitrate concentration profiles along two representative corn stalks sampled in Zhangye Basin

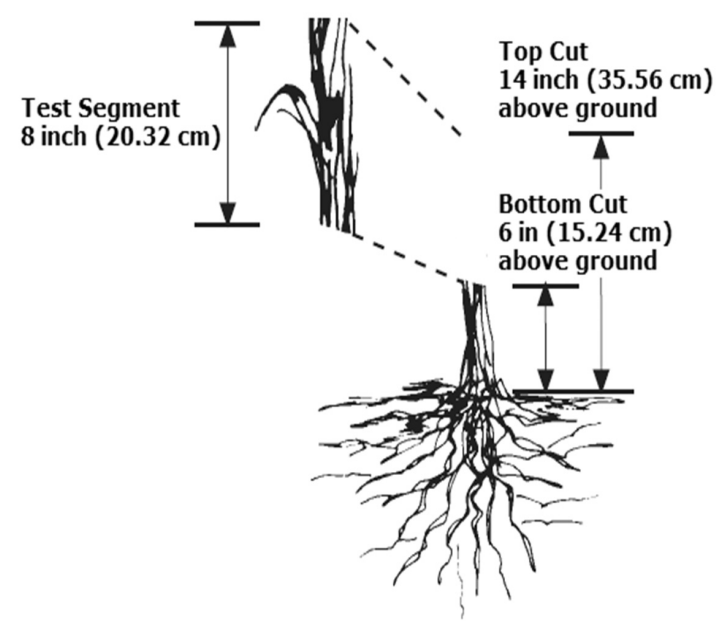

Fig. 2: Corn stalk sampling

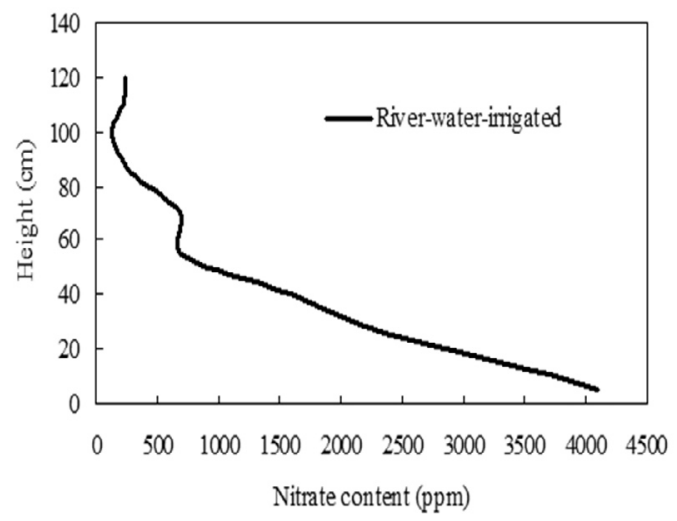

Fig. 4: Nitrate concentration profile along a corn stalk sampled in Luan County

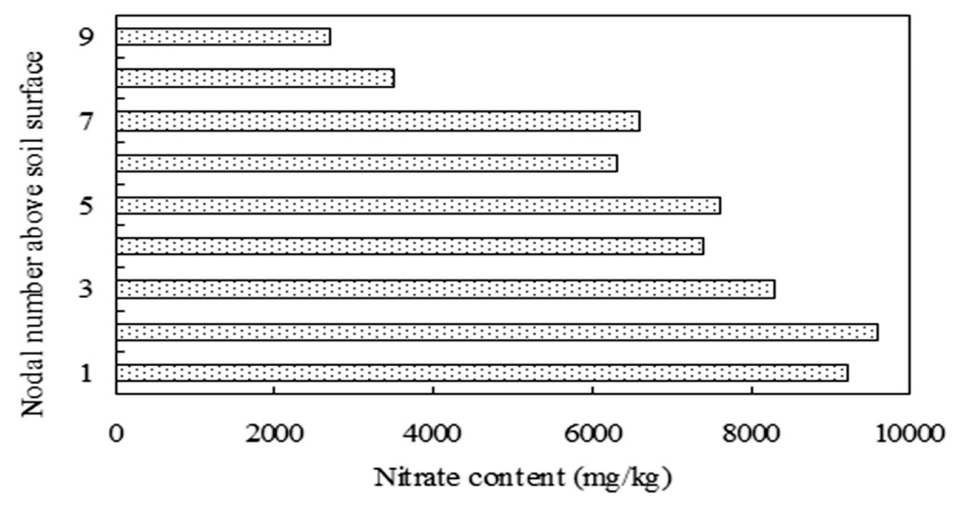

Fig. 5. Nitrate concentrations at all nodes along a corn stalk 
being kept high due to its exposure to strong and long sunshine duration in an arid climate. Thus an unfavorable thermal gradient is formed, counteracting concentration gradient within the plant. Such a mechanism results in a rapid decreasing profile of nitrate distribution, which affects the applicability of LSCNT. In the case of wastewater irrigation, the water temperature is at least several degrees higher so that it facilitates nitrate upward transport in a corn plant. A simple modification suggested by data from this study would be to cut a $20 \mathrm{~cm}$ segment of the stalk between $5 \mathrm{~cm}$ and $25 \mathrm{~cm}$ above the ground. In this way, the mean nitrate concentrations would be larger than $2000 \mathrm{mg} / \mathrm{kg}$ for both wastewater-irrigated and river-water-irrigated plans. This leads to the issue of the appropriateness of the test segment position and its length as well, to which so little attention has been paid. Obviously, a better approach to improve LSCNT would be to take into consideration of factors such as irrigation water and soil conditions. However, a large number of samples and relevant survey must be conducted for this purpose.

As a further test of LSCNT, it was used to examine the nitrate contents in corns produced in the Luan County. Fig. 4 shows the nitrate concentration distribution along a corn stalk which was irrigated with river water the in the Luan County. The mean nitrate concentration of the segment designated by LSCNT is about 2500 ppm indicating the overuse of nitrogen fertilizer. The mean nitrate concentration in the segment between $5 \mathrm{~cm}$ and $25 \mathrm{~cm}$ above the ground is $3250 \mathrm{ppm}$. It would also indicate the overuse of nitrogen fertilizer if it had been designated by LSCNT. According to Zhang et al., ${ }^{15}$, the total amount of fertilizers applied on farmlands in this region is $507 \mathrm{~kg} / \mathrm{ha}$. Since fertilizers manufactured in China have an N-P-K ratio of 1-0.62-0.002, the nitrogen fertilizer application rate in this region is about $314 \mathrm{~kg} / \mathrm{ha}$. Therefore, the LSCNT is proven useful in a region under sub-humid warm temperate continental monsoon climate as far as the current test is concerned.

In the Luan County, another attempt was made, which was to measure nitrate concentrations at all nodes along a corn stalk. As depicted in Fig. 5 , the second node above soil surface showed the maximum among the nodal nitrate concentrations along this corn stalk. Such a characteristic may deserve further study for the purpose of developing even easier diagnosis method for nitrogen fertilizer management.

\section{DISCUSSION}

\section{Implication to GHG emission reduction}

Although it has been well documented that synthetic nitrogen fertilizer is a source of groundwater water pollution, the overuse of nitrogen fertilizers is also a source of greenhouse gas (GHG) emissions. It is particularly true in China because China has become the largest producer and consumer of nitrogen fertilizer and the largest emitter of $\mathrm{CO}_{2}$ into the atmosphere as well. For every ton of nitrogen fertilizer produced and used on cropland in China, an average of $13.5 \mathrm{t}$ of $\mathrm{CO}_{2}{ }^{-}$equivalent is emitted ${ }^{16}$. Ju et al., ${ }^{17}$ estimated that total fertilizer use in China could be reduced by $30-60 \%$ without compromising yield. In the Zhangye Basin, the corn-growing area is more than 67000 ha. If the nitrogen fertilizer use is reduced from the current level of $450 \mathrm{~kg} / \mathrm{ha}$ to 150 $\mathrm{kg} / \mathrm{ha}$, a total of $135000 \mathrm{t}$ of $\mathrm{CO}_{2}-$ equivalent emission may be reduced annually from the corn production in the Zhangye Basin. To achieve such reductions all over China, the development of a quick and low cost diagnosis method will certainly help or even be crucial.

\section{Social dimension of LSCNT and the way forward}

Since 1998, Chinese government has been subsidizing fertilizer production and consumption through policies such as preferential electricity and raw material prices for fertilizer manufacturer and fertilizer price adjustment in favor of farmers. As a result, nitrogen fertilizer prices in China are lower than world prices. Furthermore, a so-called general agricultural input subsidy was created in 2006, and subsidy per unit nutrients was further increased from $300 \mathrm{RMB}$ in 2006 to $600 \mathrm{RMB}$ 2007. In view of such subsidies, Shen et al. ${ }^{18}$ suggested that national subsidy policies should be viewed as the root cause of fertilizer overuse in China. However, a more balance view should take into consideration of grain price. Indeed, Chinese government has been stabilizing both the fertilizer and grain prices. The government uses two measures to control the grain market. It purchases a large part of the grain output from farmers at fixed prices via a quota system 
and uses imports and exports to adjust the grain supply. Scrutinizing China's agricultural statistic data revealed that the ratio of the price indices of fertilizer to maize has varied slightly between 0.90 and 1.16 for the period from 1996 to 2005 . The present study also examined the ratio of fertilizer cost to the total cost of corn production per unit area and found that it had increased from $44 \%$ in 2003 to $51 \%$ in 2008. Given the facts above, the viewpoint that farmers overuse fertilizer for higher profits could not be justified. Alternatively, not being aware of the best available technologies or, not having access to them may be considered as the main cause of fertilizer overuse by Chinese farmers. Thus use of LSCNT can lead to significantly higher net income for farmers through reducing fertilizer expenditure, and help clarify what is the root cause of fertilize over-application in the same time. If the use of right technology was proven to be more effective in limiting fertilizer application than subsidy adjustment, it could prevent misguided cut of fertilizer subsidies.

Soil testing for fertilizer recommendation using methods such as ASI and Mehlich 3 was introduced into China in $1990 \mathrm{~s}^{19}$, and large-scale pilot projects to better manage fertilizer use with soil testing approach begun since $2005^{20}$. However, the soil testing has been mainly used to develop sitespecific fertilizer formula prior to planting; in-season testing to see if additional nitrogen fertilizer is needed has not received sufficient attention in China. The Pre-Sidedress Soil Nitrate Test (PSNT) developed at University of Vermont is a method available to corn grower for improving the efficiency of nitrogen fertilizer application ${ }^{21-23}$. The test should be conducted just prior to sidedressing and it determines the nitrate content available in the soil at that time. The results are then used to make sidedress nitrogen recommendations. Literature survey in Chinese publication database found no application of PSNT to China. Therefore, a strategy to make fertilizer use more profitable for corn-growing farmers is to combine the pre-season and in-season soil testing with the end-season cornstalk nitrate test. In particular, the end-season test outcomes can help improve pre-season and in-season testing methods, leading to the overall optimization of nitrogen fertilizer management.

\section{CONCLUSION}

Since the Late Season Cornstalk Nitrate Test is a quick and easy approach to diagnose nitrogen use in corn production, its application to China, whose agriculture has been based on intensive use of fertilizers for the past several decades, can help curb excessive use of nitrogen and contribute to environmental protection. However, the present study provided evidence that this approach may have to be adapted to dry continental climate and irrigation water conditions. In particular, it revealed that when the nitrate concentration gradient along a corn stalk was large, LSCNT failed in giving the right assessment of nitrogen fertilizer application. A simple downward shift in the position of the testing segment appeared to be a cure. Meanwhile, LSCNT tested well in a region under sub-humid warm temperate continental monsoon climate in China. It should emphasized here that the present study was a pioneering step to apply the LSCNT approach to regions climatically and socially different from where it was originally developed, more in-depth study with sufficiently large number of samples is indispensible to tailor it for situations in China. The importance of adapting such a practical method to China is not limited to agricultural management but far-reaching to climate change mitigation. Furthermore, by highlighting the ratio of fertilizer cost to the total cost per unit area in corn production and the grain price stabilization practice, the present paper argued that the national fertilizer subsidies could not be simply blamed as the root cause of fertilizer overuse. Finally, the present paper proposed the integration of the end-season cornstalk nitrate test with pre and inseason soil testing as a better scheme to achieve the best fertilizer management in China.

\section{ACKNOWLEDGEMENTS}

This study was partially supported by JSPS research grants for Scientific Research B (Research Project Number: 23404022). 


\section{REFERENCES}

1. Heffer P., Assessment of Fertilizer Use by Crop at the Global Level: 2006/07-2007/08. International Fertilizer Industry Association (France) (2009).

2. Chen JY, Tang CY, Sakura Y, Kondoh A, Shen YJ. Groundwater flow and geochemistry in the lower reaches of the Yellow River: a case study in Shandong Province, China. Hydrogeol. J. 10: 587-599 (2002).

3. Ju XT, Kou CL, Zhang FS, Christie P., Nitrogen balance and groundwater nitrate contamination: comparison among three intensive cropping systems on the North China Plain. Environment Pollution 143(1): 117-125 (2005).

4. Yang R, Liu W., Nitrate contamination of groundwater in an agroecosystem in Zhangye Oasis, Northwest China. Environ Earth Sci. 61: 123-129 (2010).

5. Li XY, Zuo CS, Tshirley JB, Webb SE, Morton A., Sustainable agriculture and rural development in China, part 1: the agroecosystem and China's rural economy. In, Promotion of sustainable agriculture and rural development in china: elements for a policy framework and a National Agenda 21 Programme. Available from http://www.fao. org/sd/EPdirect/EPan0009.htm (1997).

6. Blackmer, AM, Mallarino AP, Cornstalk testing to evaluate nitrogen management. lowa State University, Extension Publication PM-1584 (2000).

7. Steingrover E, Ratering P, Siesling J., Daily change in uptake, reduction and storage of nitrate in spinach grown at low light intensity. Physiol. Plant. 66: 550-556 (1986).

8. Pavlou GC, Ehaliotis CD, Kavvadias VA, Effect of organic and inorganic fertilizers applied during successive crop seasons on growth and nitrate accumulation in lettuce. Sci. Hort. 111: 319-325 (2007).

9. Wright MJ, Davison KL, Nitrate accumulation in crops and nitrate poisoning in animals. Advances in Agronomy 16: 197-247 (1964).

10. Denium B, Sibma B., Nitrate content of herbage in relation to nitrogen fertilization and management. pp. 95-102. In: Proceedings of the International Symposium of European Grassland Federation on Role of Nitrogen in Intensive Grassland Production (1980).

11. Gilbert BE, The adaptation of certain colorimetric methods to the estimation of nitrates, phosphates and potassium in plant solutions. Plant Physiol. 1(2): 191-199 (1926).

12. Su YZ, Zhang ZH, Yang R., Amount of irrigation and nitrogen application for maize grown on sandy farmland in the marginal oasis in the middle of Heihe River Basin. Acta Agron Sinica 33(1): 2007-2015 (in Chinese) (2007).

13. Sun G., Du J., Analysis of factors affecting oasis agricultural development and countermeasure in Zhangye. Pratacultural Science 29(10): 1638-1641 (2012).

14. Qin X., Study on optimal nitrogen application rate for corn production. Agricultural Technology and Information 3: 16-18 (2007). (in Chinese).

15. Zhang GH, Liu ZP, Lian YL, Yan MG, Wang $J Z$, Variation of Groundwater Quality and Influence of Pesticide and Fertilizer on Hebei Plain. South-to-North Water Transfers and Water Science \& Technology 7(2): 50-54 (2009). (in Chinese).

16. Zhang WF, et al. New technologies reduce greenhouse gas emissions from nitrogenous fertilizer in China. Proc. Natl. Acad. Sci. USA. 110(21): 8375-8380 (2012).

17. Ju XT, et al., Reducing environmental risk by improving $\mathrm{N}$ management in intensive Chinese agricultural systems. Proc. Natl. Acad. Sci. USA. 106(9): 3041-3046 (2009).

18. Shen $Y D$, Du ZQ, Wang $Y P$, Inherent mechanism on agrochemical substituting and eco-friendly agrotechnical market. Research of Agricultural Modernization 29(1): 104-107 (in Chinese) (2008).

19. Bai YL, Yang LP, 2006, Soil testing and fertilizer recommendation in chinese agriculture. Soil Fertilizer. 2: 3-7 (in Chinese).

20. Gao X., Progress and development for fertilizing by prescription filled according to soil test results in China. Chinese Journal 
of Agr icultura I Resources and Regional 22. Planning 29(1): 7-10 (2008).

21. Heckman JR, Hlubik WT, Prostak DJ, Paterson JW, Pre-sidedress soil nitrate test for sweet corn. HortScience 30: 1033-1036 (1995).
G. S. Kalwania and R. Shyam., Orient. J. Chem., 28(1): 547-552 (2012).

23. N. Akila and T. Jeyadoss., Orient. J. Chem., 26(4): 153-1360 (2010). 